\title{
Effects of a timely therapy with doxycycline on the left ventricular remodeling according to the pre-procedural TIMI flow grade in patients with ST-elevation acute myocardial infarction
}

\author{
Giampaolo Cerisano • Piergiovanni Buonamici · Renato Valenti • Guia Moschi • \\ Enrico Taddeucci • Letizia Giurlani · Angela Migliorini · Ruben Vergara • Guido Parodi • \\ Roberto Sciagrà $\cdot$ Roberta Romito $\cdot$ Paolo Colonna $\cdot$ David Antoniucci
}

Received: 7 March 2014/Revised: 23 April 2014/Accepted: 25 April 2014

(C) Springer-Verlag Berlin Heidelberg 2014

\begin{abstract}
Doxycycline has been demonstrated to reduced left ventricular (LV) remodeling, but its effect in patients with ST-elevation myocardial infarction (STEMI) and a baseline occluded [thrombolysis in myocardial infarction (TIMI) flow grade $\leq 1$ ] infarct-related artery (IRA) is unknown. According to the baseline TIMI flow grade, 110 patients with a first STEMI were divided into 2 groups. Group 1: 77 patients with TIMI flow $\leq 1$ (40 patients treated with doxycycline and 37 with standard therapy, respectively), and a Group 2: 33 patients with TIMI flow 2-3 (15 patients treated with doxycycline and 18 with standard therapy, respectively). The two randomized groups were well matched in baseline characteristics. A 2D-Echo was performed at baseline and at 6 months, together with a coronary angiography, for the remodeling and IRA patency assessment, respectively. The LV end-diastolic volume index (LVEDVi) decreased in Group $2\left[-3 \mathrm{~mL} / \mathrm{m}^{2}\right.$ (IQR: -12 to $\left.\left.4 \mathrm{~mL} / \mathrm{m}^{2}\right)\right]$, and increased in Group $1\left[6 \mathrm{~mL} / \mathrm{m}^{2}\right.$ (IQR: -2 to $\left.14 \mathrm{~mL} / \mathrm{m}^{2}\right)$ ], $(p=0.001)$. In Group 2, LVEDVi reduction was similar regardless of drug therapy, while in Group 1 the LVEDVi was smaller in patients treated with doxycycline as compared to control $\left[3 \mathrm{~mL} / \mathrm{m}^{2}\right.$
\end{abstract}

G. Cerisano $(\varangle)$ - P. Buonamici · R. Valenti · G. Moschi ·

E. Taddeucci - L. Giurlani - A. Migliorini · R. Vergara ·

G. Parodi · D. Antoniucci

Division of Cardiology, Careggi Hospital, Largo Brambilla 3,

50141 Florence, Italy

e-mail: giampaolo.cerisano@gmail.com

R. Sciagrà

Nuclear Medicine Unit, Department of Clinical

Physiopathology, University of Florence, Careggi Hospital,

Florence, Italy

R. Romito · P. Colonna

Division of Cardiology, Policlinico Hospital, Bari, Italy
(IQR: -3 to $8 \mathrm{~mL} / \mathrm{m}^{2}$ ) vs. $10 \mathrm{~mL} / \mathrm{m}^{2}$ (IQR: $1-27 \mathrm{~mL} / \mathrm{m}^{2}$ ), $p=0.006]$. A similar pattern was observed also for LV end-systolic volume and ejection fraction. In STEMI patients at higher risk, as those with a baseline TIMI flow grade $\leq 1$, doxycycline reduces $L V$ remodeling.

Keywords Acute myocardial infarction - TIMI flow grade $\cdot$ Ventricular remodeling $\cdot$ Doxycycline

In recent years, large interest has been focused on the open [thrombolysis in myocardial infarction (TIMI) flow 2-3] infarct-related artery (IRA) of patients with acute ST-elevation myocardial infarction (STEMI) before primary percutaneous coronary intervention (PCI), which may imply shorter ischemia time, a smaller infarct size [1-3], and better left ventricular (LV) function [1, 3, 4], and patient outcome [5, 6]. Conversely, an occluded IRA (TIMI flow grade $\leq 1$ ) before primary PCI, which is observed in almost $2 / 3$ of patients with STEMI [2], is associated with increased LV remodeling despite an optimal epicardial mechanical recanalization (post-PCI TIMI flow grade 3) [4]. This ominous relationship between low baseline TIMI flow grade and LV remodeling has been attributed to different factors [7-9] including a greater ischemia/reperfusion injury [10].

In patients with STEMI and LV dysfunction successfully treated with primary PCI, we recently demonstrated that a timely short-term therapy with doxycycline, the most potent metalloproteinases (MMPs) inhibitor of the tetracycline class of antibiotics, reduced both 6-month LV remodeling and infarct size [11]. Several pleiotropic properties of doxycycline related mainly to its ability to act as metalloproteinases (MMPs) inhibitor can explain these beneficial effects [12]. 
On the base of the recently performed TIPTOP (early short-term doxycycline therapy in patients with acute myocardial infarction and left ventricular dysfunction to prevent the ominous progression to adverse remodeling) randomized trial [11], we therefore set out to analyze the relationship between pre-PCI IRA TIMI flow and the 6-month LV remodeling in relation to doxycycline therapy.

\section{Methods}

Study design, patients and procedures

The TIPTOP trial has been already descripted in detail [11]. In brief, TIPTOP trial is a prospective, phase-2, single-center, randomized, open-label controlled trial in which 110 patients older than 18 years with acute STEMI and LV ejection fraction (LVEF) $<40 \%$ were randomly assigned in a 1:1 ratio to receive doxycycline or standard care. All patients were treated with primary PCI, including stenting of the IRA, and received medical therapy for STEMI and LV dysfunction in accordance with standard and recommended practice. Doxycycline (Bassado; Pfizer Italia s.r.l.) was administered at $100 \mathrm{mg}$ oral dose immediately after primary PCI and then every $12 \mathrm{~h}$ for 7 days. The antimicrobial dose we used ensures plasma levels of doxycycline similar to those obtained with higher doses used in the experimental model where the doxycycline has been proved effective in inhibiting MMPs [13], and preventing abdominal aortic aneurysm [13] and post-infarction LV remodeling $[14,15]$. The $\Sigma$ ST-segment elevation immediately before primary PCI was considered as a surrogate of the area of myocardium at risk [16]. The pre-defined primary endpoint of the TIPTOP Trial was the percent change from baseline to 6 months in echocardiographic LV end-diastolic volume index (LVEDVi).

For the present study, pre- and post-primary PCI angiographic flow grade was re-analyzed by two experts (AM and GP) who were not associated with the original trial, and who were unaware of the treatment group assignments and clinical outcomes. Blood flow in the IRA was graded according to the TIMI classification [17]. Collateral circulation was quantified according to Rentrop et al. [18]. Left ventricular remodeling was defined as the change from baseline to 6 months $(\Delta)$ in echocardiographic LVEDVi.

\section{Statistical analysis}

Discrete data were summarized as frequencies, whereas continuous data were summarized as mean $\pm \mathrm{SD}$ or median and interquartile range (IQR) when appropriate. The $x^{2}$ test or Fisher's exact test was used for comparison of categorical variables, and the unpaired and paired 2-tailed Student $t$ test or Mann-Whitney-Wilcoxon ranksum test was used to detect differences among continuous variables. Non-parametric tests were used for analyzing the non-normally distributed (Shapiro-Wilk test) baseline LVEDVi and LVESVi, $\triangle$ LVEDVi and LVESVi, $\Sigma$ STsegment elevation, troponin I peak, creatine kinase-MB peak and pro brain natriuretic peptide (pro-BNP) peak. To examine the unique contribution of doxycycline on $\mathrm{LV}$ remodeling, a hierarchical multiple regression analysis was performed, after logarithmic or square root transforming for the non-normally distributed variables. The choice of variables to be included in the multivariate model was based on a conceptual framework describing the hierarchical relationships between the major determinants that could explain the LV remodeling. The single variables that could explain LV remodeling were entered in two steps. In step 1, $\triangle$ LVEDVi was the dependent variable while age, diabetes, hypertension, $\Sigma$ ST-segment elevation pre-PCI and post-PCI (as a measure of the area at risk and myocardial reperfusion effectiveness, respectively), troponin I peak or CK-MB peak (as a measure of the infarct size), and pro-BNP peak (as a measure of LV wall stress) were the independent variables. In step 2, ACE inhibitors/ARBs, and beta adrenergic blockers, which represent the cornerstone of anti-remodeling therapy for acute STEMI patients, were entered into the step 2 equation. Finally, doxycycline was entered into the step 3 equation. All tests were two sided, and a $p$ value $<0.05$ was considered statistically significant. Analyses were performed with SPSS software, version 19 (IBM Corp, Somers, NY).

\section{Results}

\section{Baseline characteristics}

Patients were divided into two groups depending on the baseline IRA TIMI flow grade: group 1, with TIMI flow grade $\leq 1$ (77 patients), and group 2 with TIMI flow grade 2-3 (33 patients). Baseline characteristics of the patients are shown in Table 1. A TIMI flow $\leq 1$ was associated with younger age and lower prevalence of diabetes and hypertension. Reduced pre-procedural TIMI flow grade was also associated with a larger myocardial area at risk, as indirectly showed by pre-PCI $\Sigma$ ST-segment elevation.

Of the 77 patients with baseline TIMI flow grade $\leq 1,40$ patients [52\%] received doxycycline therapy (in addition to standard therapy), and 37 patients (48\%) received standard therapy, respectively. Among 33 patients with baseline TIMI flow grade $2-3,15$ patients $(45 \%)$ received doxycycline therapy (in addition to standard therapy) and 18 patients $(55 \%)$ received standard therapy, respectively. The baseline characteristics according to the TIMI flow and 
Table 1 Baseline and procedural characteristics according to the baseline TIMI flow

Continuous data are presented as mean $\pm \mathrm{SD}$ or as median [interquartile range] when appropriate

$A C E$ denotes angiotensinconverting enzyme, $A R B$ angiotensin II receptor blocker, IRA infarct-related artery, $L A D$ left anterior descending artery, $L V E F$ left ventricular ejection fraction, $L V E D V i$ left ventricular end-diastolic volume index, $L V E S V i$ left ventricular end-systolic volume index, $P C I$ primary percutaneous coronary intervention, TIMI thrombolysis in myocardial infarction, $T n I$ troponin I, $C K-M B$ creatine kinase-MB, $B N P$ brain natriuretic peptide, $\Sigma$ STe sum of ST-elevation

\begin{tabular}{|c|c|c|c|}
\hline Variables & $\begin{array}{l}\text { Group 1 (TIMI flow } \leq 1) \\
(n=77)\end{array}$ & $\begin{array}{l}\text { Group } 2 \text { (TIMI flow 2-3) } \\
(n=33)\end{array}$ & $p$ value \\
\hline Age (years) & $69 \pm 12$ & $71 \pm 10$ & 0.29 \\
\hline Male sex $(\%)$ & 71 & 64 & 0.42 \\
\hline Hypertension (\%) & 39 & 61 & 0.04 \\
\hline Diabetes $(\%)$ & 9 & 39 & 0.001 \\
\hline Dyslipidemia (\%) & 23 & 24 & 0.92 \\
\hline Smoke $(\%)$ & 39 & 36 & 0.80 \\
\hline Ischemia time (min) & $272 \pm 205$ & $280 \pm 220$ & 0.86 \\
\hline Heart rate (beats/min) & $77 \pm 14$ & $83 \pm 16$ & 0.05 \\
\hline Systolic blood pressure (mmHg) & $129 \pm 28$ & $130 \pm 29$ & 0.87 \\
\hline Killip class & $1.5 \pm 0.7$ & $1.4 \pm 0.8$ & 0.71 \\
\hline Anterior location (\%) & 91 & 97 & 0.27 \\
\hline$\Sigma$ STe pre-PCI $(\mathrm{mm})$ & $15.0[11.3-23.8]$ & $9.2[5.6-15.4]$ & 0.001 \\
\hline$\Sigma$ STe post-PCI (mm) & $5.3[3.1-10.4]$ & $3.9[1.9-4.8]$ & 0.10 \\
\hline LVEDVi (mL/m²) & $45[39-54]$ & $48[39-62]$ & 0.11 \\
\hline LVESVi (mL/m²) & $28[23-34]$ & $32[24-42]$ & 0.12 \\
\hline LVEF (\%) & $37 \pm 7$ & $36 \pm 7$ & 0.63 \\
\hline $\operatorname{LAD}(\%)$ & 90 & 91 & 0.84 \\
\hline Multivessel disease (\%) & 48 & 51 & 0.34 \\
\hline Collateral grade Rentrop1 (\%) & 1.3 & 3 & 0.53 \\
\hline $\begin{array}{l}\text { Number of treated lesions } \\
\text { (mean) }\end{array}$ & $1.5 \pm 0.7$ & $1.3 \pm 0.5$ & 0.73 \\
\hline Procedural success $(\%)$ & 100 & 100 & 1.00 \\
\hline Stenting of IRA (\%) & 100 & 100 & 1.00 \\
\hline Multiple stenting (\%) & 31 & 42 & 0.40 \\
\hline Abciximab use (\%) & 94 & 94 & 0.93 \\
\hline Total length of stenting (mm) & $22 \pm 11$ & $25 \pm 9$ & 0.21 \\
\hline $\begin{array}{l}\text { IRA TIMI flow grade } 3 \text { after } \\
\text { PCI }(\%)\end{array}$ & 100 & 100 & 1.00 \\
\hline $\begin{array}{l}\text { Symptom onset to balloon time } \\
\text { (min) }\end{array}$ & $241 \pm 203$ & $246 \pm 223$ & 0.91 \\
\hline Procedural time (min) & $32 \pm 18$ & $34 \pm 16$ & 0.49 \\
\hline TnI peak $(\mathrm{ng} / \mathrm{ml})$ & $248[119-416]$ & 84 [39-221] & 0.001 \\
\hline CK-MB (IU/L) & $316[206-450]$ & $141[76-241]$ & 0.001 \\
\hline Pro-BNP Peak (pg/mL) & $3,111[1,896-6,544]$ & $4,795[2,439-9,451]$ & 0.18 \\
\hline Aspirin (\%) & 96 & 100 & 0.61 \\
\hline Thienopyridine (\%) & 100 & 100 & 1.00 \\
\hline Statin $(\%)$ & 100 & 100 & 1.00 \\
\hline Beta adrenergic blocker $(\%)$ & 84 & 88 & 0.76 \\
\hline ACE inhibitor/ARB (\%) & 77 & 90 & 0.14 \\
\hline
\end{tabular}

month after index myocardial infarction; one patient (3\%) with baseline TIMI flow grade 2-3 in the control group died of ischemic stroke 5 months after MI. One patient with baseline TIMI flow grade $\leq 1$ in the control group had a nonfatal recurrent MI, and this patient was excluded from 6-month evaluation. Ten patients with baseline TIMI flow grade $\leq 1(13 \%)$, three in the doxycycline group $(7 \%)$ and seven in the control group (19\%), and one patient with baseline TIMI flow grade 2-3 (3\%) randomized to doxycycline group had a worsening NYHA class III-IV and/or 
Table 2 Baseline and procedural characteristics according to the baseline TIMI flow and doxycycline therapy

\begin{tabular}{|c|c|c|c|c|c|c|}
\hline & \multicolumn{2}{|c|}{ Group 1 (TIMI flow $\leq 1)(n=77)$} & \multirow[t]{2}{*}{$p$} & \multicolumn{2}{|c|}{ Group 2 (TIMI flow $2-3)(n=33)$} & \multirow[t]{2}{*}{$p$} \\
\hline & $\begin{array}{l}\text { Doxycycline } \\
(n=40)\end{array}$ & Control $(n=37)$ & & $\begin{array}{l}\text { Doxycycline } \\
(n=15)\end{array}$ & Control $(n=18)$ & \\
\hline Age (years) & $68 \pm 12$ & $70 \pm 12$ & 0.43 & $73 \pm 8$ & $69 \pm 12$ & 0.26 \\
\hline Male sex $(\%)$ & 75 & 67 & 0.47 & 67 & 61 & 0.71 \\
\hline Hypertension (\%) & 42 & 35 & 0.51 & 60 & 61 & 0.95 \\
\hline Diabetes (\%) & 7 & 11 & 0.61 & 33 & 44 & 0.51 \\
\hline Dyslipidemia (\%) & 30 & 16 & 0.15 & 27 & 22 & 0.77 \\
\hline Smoke $(\%)$ & 37 & 40 & 0.78 & 40 & 33 & 0.69 \\
\hline Ischemia time (min) & $275 \pm 192$ & $269 \pm 221$ & 0.90 & $267 \pm 139$ & $291 \pm 274$ & 0.76 \\
\hline Heart rate (beats/min) & $74 \pm 13$ & $80 \pm 15$ & 0.56 & $84 \pm 18$ & $83 \pm 15$ & 0.82 \\
\hline Systolic blood pressure (mmHg) & $129 \pm 30$ & $128 \pm 26$ & 0.85 & $133 \pm 32$ & $127 \pm 27$ & 0.58 \\
\hline Killip Class & $1.4 \pm 0.7$ & $1.5 \pm 0.7$ & 0.69 & $1.3 \pm 0.6$ & $1.5 \pm 0.9$ & 0.30 \\
\hline Anterior location (\%) & 95 & 86 & 0.19 & 100 & 94 & 0.35 \\
\hline$\Sigma$ STe pre-PCI $(\mathrm{mm})$ & $17[10-25]$ & $14[12-23]$ & 0.90 & $9.2[6-15]$ & $6[5-15]$ & 0.24 \\
\hline$\Sigma \mathrm{STe}$ post $(\mathrm{mm})$ & $6[3-11]$ & 5 [3-9] & 0.72 & $3.9[2-5]$ & $4[2-5]$ & 0.37 \\
\hline LVEDVi $\left(\mathrm{mL} / \mathrm{m}^{2}\right)$ & $45[39-54]$ & $45[39-53]$ & 0.68 & 48 [39-62] & $56[38-65]$ & 0.44 \\
\hline LVESVi $\left(\mathrm{mL} / \mathrm{m}^{2}\right)$ & $28[24-34]$ & 28 [23-35] & 0.75 & $32[24-42]$ & $34[24-45]$ & 0.41 \\
\hline LVEF (\%) & $37 \pm 7$ & $36 \pm 7$ & 0.49 & $36 \pm 7$ & $35 \pm 8$ & 0.27 \\
\hline LAD (\%) & 92 & 86 & 0.39 & 93 & 89 & 0.66 \\
\hline Multivessel disease (\%) & 30 & 32 & 0.96 & 47 & 55 & 0.48 \\
\hline Collateral grade Rentrop $1(\%)$ & 2.5 & 0 & 0.33 & 0 & 5.9 & 0.35 \\
\hline Number of treated lesions (mean) & $1.2 \pm 0.5$ & $1.3 \pm 0.6$ & 0.30 & $1.6 \pm 0.9$ & $1.4 \pm 0.6$ & 0.56 \\
\hline Procedural success $(\%)$ & 100 & 100 & 1.0 & 100 & 100 & 1.00 \\
\hline Stenting of IRA (\%) & 100 & 100 & 1.0 & 100 & 100 & 1.00 \\
\hline Multiple stenting (\%) & 30 & 32 & 0.96 & 40 & 44 & 0.65 \\
\hline Abciximab use $(\%)$ & 92 & 94 & 0.70 & 100 & 89 & 0.18 \\
\hline Total length of stenting $(\mathrm{mm})$ & $24 \pm 11$ & $21 \pm 11$ & 0.28 & $25 \pm 9$ & $25 \pm 9$ & 0.88 \\
\hline TIMI flow grade 3 after PCI (\%) & 100 & 100 & 1.0 & 100 & 100 & 1.0 \\
\hline Symptom onset to balloon time (min) & $243 \pm 187$ & $238 \pm 222$ & 0.92 & $234 \pm 142$ & $256 \pm 178$ & 0.77 \\
\hline Procedural time (min) & $32 \pm 20$ & $31 \pm 16$ & 0.75 & $33 \pm 16$ & $35 \pm 17$ & 0.73 \\
\hline TnI peak (ng/ml) & $211[97-413]$ & $322[167-418]$ & 0.10 & $83[30-228]$ & 99 [42-224] & 0.61 \\
\hline CK-MB (IU/liter) & $302[165-437]$ & $194[209-485]$ & 0.52 & $128[43-265]$ & $142[87-307]$ & 0.42 \\
\hline Pro-BNP Peak (pg/mL) & $2,094[1,671-5,887]$ & $3,314[2,002-4,846]$ & 0.41 & $4,195[1,405-6,743]$ & $4,983[3,470-10,880]$ & 0.39 \\
\hline Aspirin $(\%)$ & 98 & 94 & 0.94 & 100 & 100 & 1.00 \\
\hline Thienopyridine (\%) & 100 & 100 & 1.00 & 100 & 100 & 1.00 \\
\hline Statin $(\%)$ & 100 & 100 & 1.00 & 100 & 100 & 1.00 \\
\hline Beta adrenergic blocker (\%) & 85 & 86 & 0.85 & 93 & 89 & 0.65 \\
\hline ACE inhibitor/ARB (\%) & 79 & 73 & 0.65 & 87 & 94 & 0.87 \\
\hline
\end{tabular}

Continuous data are presented as mean $\pm \mathrm{SD}$ or as median [interquartile range] when appropriate

$A C E$ denotes angiotensin-converting enzyme, $A R B$ angiotensin II receptor blocker, IRA infarct-related artery, $L A D$ left anterior descending artery, $L V E F$ left ventricular ejection fraction, $L V E D V i$ left ventricular end-diastolic volume index, $L V E S V i$ left ventricular end-systolic volume index, $P C I$ primary percutaneous coronary intervention, $T I M I$ thrombolysis in myocardial infarction, $T n I$ troponin I, $C K-M B$ creatine kinase-MB, $B N P$ brain natriuretic peptide, $\Sigma$ STe sum of ST-elevation

hospital readmission for congestive heart failure. Overall, the rate of composite of death, myocardial infarction and congestive heart failure was $19 \%$ within the group with baseline TIMI flow grade $\leq 1$ ( $30 \%$ in the control group and
$10 \%$ in the doxycycline group, respectively; $p=0.04)$, and $9 \%$ within the group with baseline TIMI flow grade 2-3 (11\% in the control group and $7 \%$ in the doxycycline group, respectively; $p=1.0$ ). Out of the 104 survived patients, 66 
Table 3 Six-month echocardiographic analysis according to the baseline TIMI flow

\begin{tabular}{llll}
\hline & $\begin{array}{l}\text { Group 1 } \\
\text { (TIMI flow } \leq 1)\end{array}$ & $\begin{array}{l}\text { Group 2 } \\
\text { (TIMI flow 2-3) }\end{array}$ & $p$ \\
\hline $\begin{array}{l}\text { Echocardiographic } \\
\text { analysis }\end{array}$ & $n=66$ & $n=31$ & \\
$\Delta$ LVEDVi $\left(\mathrm{mL} / \mathrm{m}^{2}\right)$ & $6[-2$ to 14$]$ & $-3[-12$ to 4$]$ & 0.001 \\
$\Delta$ LVESVi $\left(\mathrm{mL} / \mathrm{m}^{2}\right)$ & $-0.5[-7$ to 8$]$ & $-9[-13$ to -1$]$ & 0.001 \\
$\Delta$ LVEF $(\%)$ & $8 \pm 10$ & $15 \pm 11$ & 0.003 \\
\hline
\end{tabular}

Continuous data are presented as mean $\pm \mathrm{SD}$ or as median [interquartile range] when appropriate

$\triangle L V E D V i$ change of left ventricular end-diastolic volume index, $\triangle L V E S V i$ change of left ventricular end-systolic volume index, $\triangle L V E F$ change of left ventricular ejection fraction

patients ( $86 \%$ ) with baseline TIMI flow grade $\leq 1$ (54\% in the doxycycline group and $46 \%$ in the control group, respectively), and 31 patients (94\%) with baseline TIMI flow grade $2-3$ (48 \% in the doxycycline group and $52 \%$ in the control group) had 6-month echocardiographic examinations suitable for the ventricular volume analysis (follow-up rate $93 \%$ ).

Echocardiographic findings

The LVEDVi decreased from baseline to 6 months in the patients with baseline TIMI flow grade $2-3\left[-3 \mathrm{~mL} / \mathrm{m}^{2}\right.$ (IQR: -12 to $4 \mathrm{~mL} / \mathrm{m}^{2}$ )], while increased in those with baseline TIMI flow grade $\leq 1\left[6 \mathrm{~mL} / \mathrm{m}^{2}\right.$ (IQR: -2 to $\left.\left.14 \mathrm{~mL} / \mathrm{m}^{2}\right)\right], \quad(p=0.001) \quad$ (Table 3). However, while LVEDVi decrease from baseline to 6 months in the group with TIMI flow grade 2-3 was similar regardless of drug therapy, in the group with baseline TIMI flow grade $\leq 1$, the increase in LVEDVi was very low and significantly lower in the doxycycline group as compared to the control group $\left[3 \mathrm{~mL} / \mathrm{m}^{2}\right.$ (IQR: -3 to $8 \mathrm{~mL} / \mathrm{m}^{2}$ ) vs. $10 \mathrm{~mL} / \mathrm{m}^{2}$ (IQR: $1-27 \mathrm{~mL} / \mathrm{m}^{2}$ ), $p=0.006$ ] (Fig. 1).

The LVESVi from baseline to 6 months decreased significantly more in the group with baseline TIMI flow grade 2-3 than in the group with baseline TIMI flow grade $\leq 1$ [ $-9 \mathrm{~mL} / \mathrm{m}^{2}$ (IQR: -13 to $-1 \mathrm{~mL} / \mathrm{m}^{2}$ ) and $-0.5 \mathrm{~mL} / \mathrm{m}^{2}$ (IQR: -7 to $8 \mathrm{~mL} / \mathrm{m}^{2}$ ), respectively, $p=0.001$ ] (Table 3 ). Particularly, in the group with baseline TIMI flow grade 2-3 LVESVi was reduced at 6 months regardless of drug therapy, while in the group with baseline TIMI flow grade $\leq 1$ it had an opposite trend: it was reduced in the doxycycline group, while it increased in the control group [ $-3 \mathrm{~mL} / \mathrm{m}^{2}$ (IQR: -10 to $3 \mathrm{~mL} / \mathrm{m}^{2}$ ) vs. 4 (IQR: -2 to $\left.14 \mathrm{~mL} / \mathrm{m}^{2}\right), p=0.002$ ] (Fig. 1).

The increase of LVEF was significantly greater in the patients with baseline TIMI flow grade $2-3$ compared to the patients with baseline TIMI flow grade $\leq 1$ (15 \pm 11 vs.
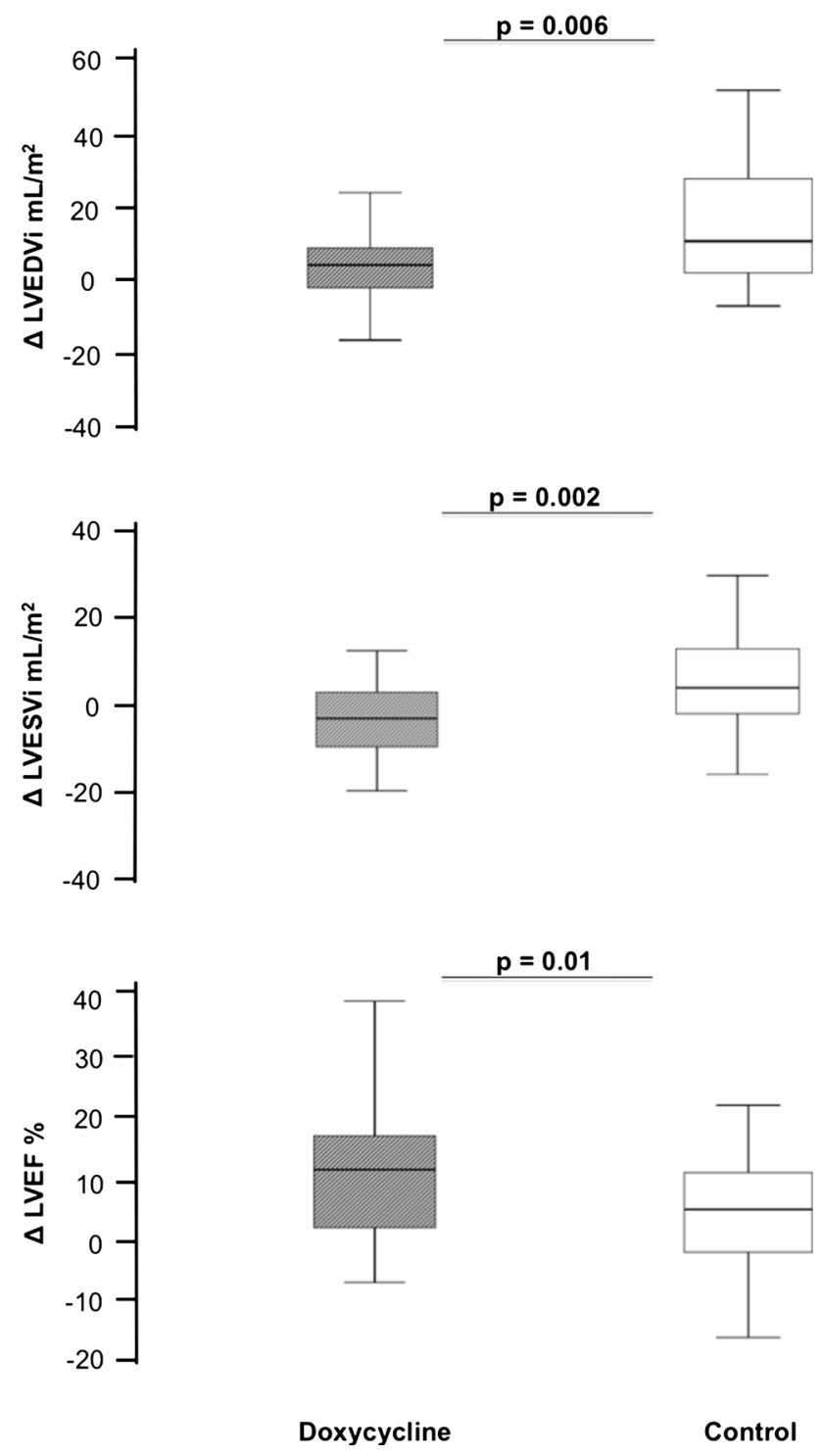

Fig. 1 Echocardiographic changes from baseline to 6 months in the group of patients with baseline TIMI flow grade $\leq 1$ according to the study therapy. The box comprises the interquartile range. The line in the box is the median. The whiskers extend downwards to the lowest value in the distribution and upwards to the largest value

$8 \pm 10 \%, p=0.003$ ) (Table 3) and, among patients with baseline TIMI flow grade $\leq 1$, in the doxycycline group respect to the control group $(11 \pm 11$ and $4 \pm 9 \%$, respectively, $p=0.01$ ) (Fig. 1).

Angiographic findings

A post-PCI TIMI flow grade 3 was achieved in all patients. The 6-month angiographic follow-up rate was $85 \%$. The IRA patency was observed in all patients with TIMI flow grade 2-3 and in all but one in those with TIMI flow grade $\leq 1$; there was no difference in binary restenosis $>50 \%$ rate according to 
Table 4 A and B Hierarchical multiple regression analysis of LVEDVi change from baseline to 6 months in the patients with baseline TIMI flow grade $\leq 1$ correcting first for age, diabetes, hypertension, $\Sigma$ STe pre-
PCI and post-PCI, Troponin I peak (A) or CK-MB peak (B), pro- BNP peak, before entering ACE inhibitor/ARB and beta adrenergic blocker at step 2 , and then doxycycline at step 3

\begin{tabular}{|c|c|c|c|c|c|c|}
\hline Step & Variables & $R$ & $R^{2}$ & $R^{2}$ change & $F$ change & $p$ \\
\hline \multicolumn{7}{|l|}{ A } \\
\hline 1 & Age, diabetes, hypertension, $\Sigma$ STe pre-PCI and post-PCI, troponin I peak, pro-BNP peak & 0.62 & 0.39 & 0.39 & 4.25 & 0.001 \\
\hline 2 & $\mathrm{ACE}$ inhibitor/ARB, beta adrenergic blocker & 0.64 & 0.41 & 0.02 & 0.75 & 0.48 \\
\hline 3 & Doxycycline & 0.68 & 0.47 & 0.06 & 4.71 & 0.03 \\
\hline \multicolumn{7}{|l|}{ B } \\
\hline 1 & Age, diabetes, hypertension, $\Sigma$ STe pre-PCI and post-PCI, CK-MB peak, pro-BNP peak & 0.61 & 0.37 & 0.37 & 3.91 & 0.002 \\
\hline 2 & ACE inhibitor/ARB, beta adrenergic blocker & 0.62 & 0.39 & 0.02 & 0.79 & 0.46 \\
\hline 3 & Doxycycline & 0.68 & 0.46 & 0.07 & 5.56 & 0.02 \\
\hline
\end{tabular}

$\overline{\Sigma S T e}$ sum of ST-elevation, $P C I$ primary percutaneous coronary intervention, $B N P$ brain natriuretic peptide, $A C E$ denotes angiotensin-converting enzyme, $A R B$ angiotensin II receptor blocker, $C K-M B$ creatine kinase-MB

study therapy in both groups: 17 vs. $18 \%(p=1.0)$ in the group with TIMI flow grade $\leq 1$, and 33 vs. $22 \%(p=0.69)$ in the group with TIMI flow grade $2-3$, respectively.

Contribution of doxycycline in LV remodeling in patients with baseline TIMI flow $\leq 1$

In Table 4A, the regression model is shown. The results of step 1 indicate that the variance accounted for $R^{2}$ with the first seven independent variables (age, diabetes, hypertension, $\Sigma$ ST-segment elevation pre-PCI and post-PCI, troponin I peak and pro-BNP peak), equaled to 0.39 which was significantly different from zero ( $F$ change $=4.25$, $p=0.001$ ). The step 2 (ACE inhibitors/ARBs, and beta adrenergic blockers) did not significantly improved the model $(p=0.48)$. By introducing the doxycycline in step 3 , the change in variance $\left(\Delta R^{2}\right)$ was equal to 0.06 , which was statistically significant $(F$ change $=4.71, p=0.03$ ). The results are similar when we used CK-MB peak as a measure of the infarct size (Table 4B).

\section{Discussion}

This study shows that in patients with a first STEMI and baseline occluded IRA, a timely short-term treatment with doxycycline significantly reduces 6-month LV remodeling.

Our data showed that persistence of residual blood flow in the IRA is associated with a lower risk area, as indirectly evaluated by pre-PCI $\Sigma$ ST-segment elevation. This finding is in agreement with what has been reported by Clements et al. [1] and Ndrepepa et al. [3] by means of refined imaging techniques. Earlier IRA blood-flow restoration, whether spontaneously or pharmacologically induced, may explain differences in the initial area of myocardium at risk.

In agreement with previous studies [1, 3, 4] and with the latest results obtained by De Luca et al. [2] on a large series of over 790 patients treated by primary PCI, we also observed that pre-procedural TIMI flow grade significantly affected enzymatic final infarct size, even when an optimal TIMI flow grade 3 post-PCI was obtained. This ominous relationship between low baseline TIMI flow grade and infarct size has been attributed to different factors resulting from the longer time of ischemia [8], as well as microembolization [7], blood clots and platelet plugs in the microcirculation [9], and a greater myocardial reperfusion injury [10]. Thus, it is not surprising that, in our study, the patients with a baseline TIMI flow grade $\leq 1$ showed a more severe ventricular remodeling than patients with a baseline TIMI flow grade 2-3.

The best characterized non-antimicrobial property of the doxycycline is its ability to inhibit members of the MMP family of endopeptidases [12], many of which are largely up-regulated in the setting of animal [19-21] and human [22, 23] hearts after MI. Previous studies have also shown that doxycycline has some ability to inhibit reactive oxygen species (ROS) [24]. Although we cannot exclude the possibility that doxycycline may have other protective effects because of its reported pleiotropic actions including inhibition of proinflammatory cytokines and ROS, it is plausible that, to the plasma concentration achievable with the dose of doxycycline used in our study [13], MMP inhibition, as opposed to ROS scavenging, may be the main mechanism of its protective action [25]. Results of preclinical studies show that the use of doxycycline in the first 7 days post-MI may exert a cardioprotective effect reducing LV remodeling [14, 15] and infarct size [26-28]. Recently, the TIPTOP trial confirmed the benefit of 
doxycycline for the first time in the clinical setting of acute STEMI [11]. In this post hoc analysis of the TIPTOP trial, doxycycline was effective in reducing $L V$ remodeling in patients with acute STEMI and pre-PCI IRA TIMI flow grade $\leq 1$. Speculatively our results further support the idea that doxycycline can exert some cardioprotective effects in this clinical setting. Further future experimental and clinical studies will answer the question whether doxycycline has any effect on ROS generation or only acts downstream of these blocking MMP proteolytic activity [29].

To examine the unique contribution of doxycycline in the explanation of LV remodeling among patients with TIMI flow grade $\leq 1$, a hierarchical multiple regression analysis was performed. The anti-remodeling effect of doxycycline was independent from both the infarct size (as measured by troponin I peak or CK-MB peak) and LV wall stress (as indirectly expressed by pro-BNP peak), which are the two most important drivers of the post-infarct remodeling process [30], and from advanced age that may critically contribute to remodeling process [31]. Moreover, doxycycline appears to have more impact on LV remodeling than the cornerstone of post-MI anti-remodeling therapy probably because the unquestionable favorable clinical effect of the latter drugs in patients with acute MI depends on mechanisms other than inhibiting the LV dilation [32], especially in the successfully reperfused patients [33].

Noteworthy, the anti-remodeling effect of doxycycline occurs in patients with a baseline TIMI flow grade $\leq 1$ but not in those with a baseline TIMI flow grade 2-3. Likewise, in the METOCARD-CNIC (effect of early metoprolol on infarct size in ST-segment elevation myocardial infarction patients undergoing primary $\mathrm{PCI}$ ) trial [34] the infarct size in the subgroup of patients with pre-PCI TIMI flow grade $\leq 1$ was reduced by metoprolol to a larger extent than in the entire study population. In other words, in the low-risk patients with acute STEMI, such as those with a baseline TIMI flow grade $>1$, the powerful salvaging capacity of primary PCI with routine use of modern antithrombotic drugs overwhelms the benefits of additional pharmacological cardioprotective strategies, which could otherwise show benefit in patients known to be at higher risk, such as those with TIMI flow grade $\leq 1$. The same finding has been demonstrated with remote ischemic conditioning $[35,36]$, supporting that in high risk patients the highest benefit beyond opening of the IRA is achieved by additional intervention, that may be pharmacological or mechanical [37-40].

Finally, pro-BNP level was higher in patients with TIMI flow grade $2-3$ on admission. This difference is nonsignificant. However, it could be explained by a higher prevalence of diabetes [2] in baseline open artery patients, and diabetes per se is a strong factor for increased plasma pro-BNP level after myocardial infarction [41]. However, at the multivariable analysis the anti-remodeling effect of doxycycline is found to be independent also from proBNP level.

The present analysis is subjected to some limitations. First, this is a post hoc analysis of a small trial and the results can be considered only hypothesis generating. Second, without an assessment of infarct size by perfusion imaging at baseline, a selection bias favoring doxycycline therapy arm cannot be excluded. However, the indirect measures of the area at risk, myocardial reperfusion effectiveness, and enzymatic infarct size did not differ between groups. Third, the patients were treated with standard-of-care therapy for STEMI, accordingly to the current ESC guidelines, with the exception of the mineralocorticoid antagonists which were used in one-fourth of the patients with the indication to this specific treatment; this was in part due to the temporal trend of study enrollment that started in early 2007, almost 2 years before the implementation of the use of MRA in the ESC guidelines for STEMI patient [42]. It is, therefore, possible that the magnitude of the benefit we have observed with doxycycline might be reduced by treating with a MRA all the patients with this indication. Fourth, 7 survived patients $(6.3 \%)$ were lost to 6-month echocardiographic follow-up. There were no significant differences between participants who were lost to follow-up and all those who were included in the present study in terms of baseline characteristics. Therefore, the potential bias regarding the participants lost to follow-up may be negligible.

In conclusion, timely administration of doxycycline in the STEMI patients at higher risk, as those with a baseline occluded IRA, is associated with a significant reduction in $\mathrm{LV}$ remodeling as compared to control.

Acknowledgments The study was not supported by any public grant or industry support.

Conflict of interest The authors declare that they have no conflict of interest.

\section{References}

1. Clements IP, Christian TF, Higano ST, Gibbons RJ, Gersh BJ (1993) Residual flow to the infarct zone as a determinant of infarct size after direct angioplasty. Circulation 88:1527-1533. doi:10.1161/01.CIR.88.4.1527

2. De Luca G, Parodi G, Sciagrà R, Venditti F, Bellandi B, Vergara R, Migliorini A, Valenti R, Antoniucci D (2013) Preprocedural TIMI flow and infarct size in STEMI undergoing primary angioplasty. J Thromb Thrombolysis. doi:10.1007/s11239-013-0977$\mathrm{x}$ (in press)

3. Ndrepepa G, Kastrati A, Schwaiger M, Mehilli J, Markwardt C, Dibra A, Dirschinger J, Schömig A (2005) Relationship between residual blood flow in the infarct-related artery and scintigraphic infarct size, myocardial salvage, and functional recovery in patients with acute myocardial infarction. J Nucl Med 46:1782-1788 
4. Leoncini M, Bellandi F, Sciagrà R, Maioli M, Toso A, Sestini S, Coppola A, Mennuti A, Dabizzi RP, Pupi A (2004) Use of 99mTc-sestamibi gated SPECT to assess the influence of anterograde flow before primary coronary angioplasty on tissue salvage and functional recovery in acute myocardial infarction. Eur J Nucl Med Mol Imaging 31:1378-1385. doi:10.1007/s00259004-1595-9

5. Brodie BR, Stuckey TD, Hansen C, Muncy D (2000) Benefit of coronary reperfusion before intervention on outcomes after primary angioplasty for acute myocardial infarction. Am J Cardiol 85:13-18. doi:10.1016/S0002-9149(99)00598-6

6. Stone GW, Cox D, Garcia E, Brodie BR, Morice MC, Griffin J, Mattos L, Lansky AJ, O'Neill WW, Grines CL (2001) Normal flow (TIMI-3) before mechanical reperfusion therapy is an independent determinant of survival in acute myocardial infarction: analysis from the primary angioplasty in myocardial infarction trials. Circulation 104:636-641. doi:10.1161/hc3101. 093701

7. Garcia-Dorado D, Theroux P, Elizaga J, Galinanes S, Solares J, Riesgo M, Gomez MJ, Garcia-Dorado A, Fernandez Aviles F (1987) Myocardial infarction in the pig heart model: infarct size and duration of coronary occlusion. Cardiovasc Res 21:537-544. doi:10.1093/cvr/21.7.537

8. Reimer KA, Vander Heide RS, Richard VJ (1993) Reperfusion in acute myocardial infarction: effects of timing and modulating factors in experimental models. Am J Cardiol 2:13G-21G. doi:10.1016/0002-9149(93)90102-I

9. Silvain J, Collet JP, Nagaswami C, Beygui F, Edmondson KE, Bellemain-Appaix A, Cayla G, Pena A, Brugier D, Barthelemy O, Montalescot G, Weisel JW (2011) Composition of coronary thrombus in acute myocardial infarction. J Am Coll Cardiol 57:1359-1361. doi:10.1016/j.jacc.2010.09.077

10. Ortiz-Pérez JT, Lee DC, Meyers SN, Davidson CJ, Bonow RO, Wu E (2010) Determinants of myocardial salvage during acute myocardial infarction: evaluation with a combined angiographic and CMR myocardial salvage index. JACC Cardiovasc Imaging 3:491-500. doi:10.1016/j.jcmg.2010.02.004

11. Cerisano G, Buonamici $\mathrm{P}$, Valenti R, Sciagrà R, Raspanti $\mathrm{S}$, Santini A, Carrabba N, Dovellini EV, Romito R, Pupi A, Colonna P, Antoniucci D (2014) Early short-term doxycycline therapy in patients with acute myocardial infarction and left ventricular dysfunction to prevent the ominous progression to adverse remodelling: the TIPTOP trial. Eur Heart J 35:184-191. doi:10. 1093/eurheartj/eht420

12. Griffin MO, Fricovsky E, Ceballos G, Villarreal FJ (2010) Tetracycline, a pleiotropic family of compounds with promising therapeutic properties. Review of the literature. Am J Physiol Cell Physiol 539:C539-C548. doi:10.1152/ajpcell.00047.2010

13. Prall AK, Longo GM, Mayhan WG, Waltke EA, Fleckten B, Thompson RW, Baxter BT (2002) Doxycycline in patients with abdominal aneurysms and in mice: comparison of serum levels and effect on aneurysm growth in mice. J Vasc Surg 35:923-929. doi: $10.1067 / m v a .2002 .123757$

14. Garcia RA, Go KV, Villarreal FJ (2007) Effects of timed administration of doxycycline or methylprednisolone on postmyocardial infarction remodeling inflammation and left ventricular remodeling in the rat heart. Mol Cell Biochem 300:159-169. doi:10.1007/s11010-006-9379-0

15. Villarreal FJ, Griffin M, Omens J, Dillmann W, Nguyen J, Covell J (2003) Early short-term treatment with doxycycline modulates postinfarction left ventricular remodeling. Circulation 108:1487-1492. doi:10.1161/01.CIR.0000089090.05757.34

16. Schröder R, Dissmann R, Brüggemann T, Wegscheider K, Linderer T, Tebbe U, Neuhaus KL (1994) Extent of early ST segment elevation resolution: a simple but strong predictor of outcome in patients with AMI. J Am Coll Cardiol 24:384-391. doi:10.1016/0735-1097(94)90292-5

17. TIMI Study Group (1985) The thrombolysis in myocardial infarction (TIMI) trial. Phase I findings. TIMI Study Group. N Engl J Med 312:932-936. doi:10.1056/NEJM198504043121435

18. Rentrop KP, Cohen M, Blanke H, Phillips RA (1985) Changes in collateral channel filling immediately after controlled coronary artery occlusion by an angioplasty balloon in human subjects. J Am Coll Cardiol 5:587-592. doi:10.1016/S0735-1097(85) 80380-6

19. Ducharme A, Frantz S, Aikava M, Rabkin E, Lindsey M, Rodhe LE, Schoen FJ, Kelly RA, Werb Z, Libby P, Lee RT (2000) Targeted deletion of matrix metalloproteinase- 9 attenuates left ventricular enlargement and collagen accumulation after experimental myocardial infarction. J Clin Invest 106:55-62. doi:10. 1172/JCI8768

20. Matsumura S, Iwanaga S, Mochizuki S, Okamoto H, Ogawa S, Okada Y (2005) Targeted delection or pharmacological inhibition of MMP-2 prevents cardiac rupture after myocardial infarction in mice. J Clin Invest 115:599-609. doi:10.1172/JCI22304

21. Mukherjee R, Widener CE, Brinsa TA, Dowdy KB, Scott AA, Sample JA, Hendrick JW, Escobar GP, Joffs C, Lucas DG, Zile MR, Spinale FG (2003) Myocardial infarct expansion and matrix metalloproteinase inhibition. Circulation 107:618-625. doi:10. 1161/01.CIR.0000046449.36178.00

22. Kelly D, Cockerill G, Ng LL, Thompson M, Khan S, Samani NJ, Squire LB (2007) Plasma matrix metalloproteinase-9 and left ventricular remodeling after acute myocardial infarction in man: a prospective cohort study. Eur Heart J 28:711-718. doi:10.1093/ eurheartj/ehm003

23. Webb CS, Bonnema DD, Ahmed SH, Leonardi AH, McClure CD, Clark LL, Stround RE, Corn C, Finklea L, Zile MR, Spinale FG (2006) Specific temporal profile of matrix metalloproteinase release occurs in patients after myocardial infarction: relation to left ventricular remodeling. Circulation 114:1020-1027. doi:10. 1161/CIRCULATIONAHA.105.600353

24. Ramamurthy NS, Vernillo AT, Greenwald RA, Lee HM, Sorsa T, Golub LM, Rifkin BR (1993) Reactive oxygen species activate and tetracyclines inhibit rat osteoblast collagenase. J Bone Miner Res 8:1247-1253. doi:10.1002/jbmr.5650081013

25. Yaras N, Sariahmetoglu M, Bilginoglu A, Aydemir-Koksoy A, Onay-Besikci A, Turan B, Schulz R (2008) Protective action of doxycycline against diabetic cardiomyopathy in rats. Br J Pharmacol 155:1174-1184. doi:10.1038/bjp.2008.373

26. Cheung PY, Sawicki G, Wozniak M, Wang W, Radomski MW, Schulz R (2000) Matrix metalloproteinase-2 contributes to ischemia/reperfusion injury in the heart. Circulation 101:1833-1839. doi:10.1161/01.CIR.101.15.1833

27. Donato M, D'Annunzio V, Buchholz B, Miksztowicz V, Carrion CL, Valdez LB, Zaobornyj T, Schreier L, Wikinski R, Boveris A, Berg G, Gelpi J (2010) Role of matrix metalloproteinase-2 in the cardioprotective effect of ischemic postconditioning. Exp Physiol 95:274-281. doi:10.1113/expphysiol.2009.049874

28. Wang W, Schulze CJ, Suarez-Pinzon WL, Dyck JR, Sawicki G, Schulz R (2002) Intracellular actions of matrix metalloproteinase- 2 accounts for acute myocardial ischemia and reperfusion injury. Circulation 106:1543-1549. doi:10.1161/01.CIR.00000 28818.33488.7B

29. Schulz R (2007) Intracellular targets of matrix metalloproteinase2 in cardiac disease: rationale and therapeutic approaches. Annu Rev of Pharmacol Toxicol 47:211-242. doi:10.1146/annurev. pharmtox.47.120505.105230

30. Braunwald E (1997) Heart Disease. A textbook of cardiovascular medicine, 5th edn. WB Saunders Company, Philadelphia, pp 1195-1196 
31. Lehrke S, Nazhari R, Durand DJ, Zheng M, Bedja D, Zimmet JM, Schuleri KH, Chi AS, Gabrielson KL, Hare JM (2006) Aging impairs the beneficial effect of granulocyte colony-stimulating factor and stem cell factor on post-myocardial infarction remodeling. Circ Res 99:553-560. doi:10.1161/01.RES. 0000238375.88582.d8

32. Cohn JN (1995) Structural basis for heart failure. Ventricular remodeling and its pharmacological inhibition. Circulation 91:2504-2507. doi:10.1161/01.CIR.91.10.2504

33. de Kam PJ, Voors AA, van den Berg MP, van Veldhuisen DJ, Brouwer J, Crijns HJ, Borghi C, Ambrosioni E, Hochman JS, LeJemtel TH, Kingma JH, Sutton MS, van Gilst WH (2000) Effect of very early angiotensin-converting enzyme inhibition on left ventricular dilation after myocardial infarction in patients receiving thrombolysis: results of a meta-analysis of 845 patients. FAMIS, CAPTIN and CATS Investigators. J Am Coll Cardiol 36:2047-2053. doi:10.1016/S0735-1097(00)01024-X

34. Ibanez B, Macaya C, Sánchez-Brunete V, Pizarro G, FernándezFriera L, Mateos A, Fernández-Ortiz A, García-Ruiz JM, GarcíaÁlvarez A, Iñiguez A, Jiménez-Borreguero J, López-Romero P, Fernández-Jiménez R, Goicolea J, Ruiz-Mateos B, Bastante T, Arias M, Iglesias-Vázquez JA, Rodriguez MD, Escalera N, Acebal C, Cabrera JA, Valenciano J, Pérez de Prado A, FernándezCampos MJ, Casado I, García-Rubira JC, García-Prieto J, SanzRosa D, Cuellas C, Hernández-Antolín R, Albarrán A, FernándezVázquez F, de la Torre-Hernández JM, Pocock S, Sanz G, Fuster V (2013) Effect of early metoprolol on infarct size in ST-segmentelevation myocardial infarction patients undergoing primary percutaneous coronary intervention: the effect of metoprolol in cardioprotection during an acute myocardial infarction (METOCARD-CNIC) trial. Circulation 128:1495-1503. doi:10.1161/ CIRCULATIONAHA.113.003653

35. Bøtker HE, Kharbanda R, Schmidt MR, Bøttcher M, Kaltoft AK, Terkelsen CJ, Munk K, Andersen NH, Hansen TM, Trautner S, Lassen JF, Christiansen EH, Krusell LR, Kristensen SD, Thuesen L, Nielsen SS, Rehling M, Sørensen HT, Redington AN, Nielsen TT (2010) Remote ischaemic conditioning before hospital admission, as a complement to angioplasty, and effect on myocardial salvage in patients with acute myocardial infarction: a randomised trial. Lancet 375:727-734. doi:10.1016/S01406736(09)62001-8

36. Munk K, Andersen NH, Schmidt MR, Nielsen SS, Terkelsen CJ, Sloth E, Bøtker HE, Nielsen TT, Poulsen SH (2010) Remote ischemic conditioning in patients with myocardial infarction treated with primary angioplasty: impact on left ventricular function assessed by comprehensive Echocardiography and gated single-photon emission CT. Circ Cardiovasc Imaging 3:656-662. doi:10.1161/CIRCIMAGING.110.957340 (Epub 2010 Sep 8)

37. Heusch G (2013) Cardioprotection: chances and challenges of its translation to the clinic. Lancet 381:166-175. doi:10.1016/S01406736(12)60916-7

38. Heusch G, Kleinbongard P, Skyschally A (2013) Myocardial infarction and coronary microvascular obstruction: an intimate, but complicated relationship. Basic Res Cardiol 108:380. doi:10. 1007/s00395-013-0380-y

39. Longacre LS, Kloner RA, Arai AE, Baines CP, Bolli R, Braunwald E, Downey J, Gibbons RJ, Gottlieb RA, Heusch G, Jennings RB, Lefer DJ, Mentzer RM, Murphy E, Ovize M, Ping P, Przyklenk K, Sack MN, Vander Heide RS, Vinten-Johansen J, Yellon DM (2011) New horizons in cardioprotection: recommendations From the 2010 national heart, lung, and blood institute workshop. Circulation 124:1172-1179. doi:10.1161/ CIRCULATIONAHA.111.032698

40. Ovize M, Baxter GF, Di Lisa F, Ferdinandy P, Garcia-Dorado D, Hausenloy DJ, Heusch G, Vinten-Johansen J, Yellon DM, Schulz R, Working Group of Cellular Biology of Heart of European Society of Cardiology (2010) Postconditioning and protection from reperfusion injury: where do we stand? Position paper from the Working Group of Cellular Biology of the Heart of the European Society of Cardiology. Cardiovasc Res 87:406-423. doi: $10.1093 / \mathrm{cvr} / \mathrm{cvq} 129$

41. Vergès B, Zeller M, Beer JC, Cottin Y, RICO survey working group (2008) Plasma N-terminal Pro-Brain Natriuretic Peptide (Nt-proBNP) level and prognosis after myocardial infarction in diabetes. Diabetes Metab 34:10-15. doi:10.1016/S1262-3636 (08)70097-1

42. Van deWerf F, Bax J, Betriu A, Blomstrom-Lundqvist C, Crea F, Falk V, Filippatos G, Fox K, Huber K, Kastrati A, Rosengren A, Steg PG, Tubaro M, Verheugt F, Weidinger F, Weis M (2008) Management of acute myocardial infarction in patients presenting with persistent ST-segment elevation. The Task Force on the management of ST-segment elevation acute myocardial infarction of the European Society of Cardiology. Eur Heart J 29:2909-2945. doi:10.1093/eurheartj/ehn416 